\title{
SURVEYS AND WORKING PLANS FOR OPERATING COMPANIES ${ }^{1}$
}

\author{
By GEORge SONLEY \\ Chief Forester, Marathon Paper Mills of Canada Limited, \\ Port Arthur, Ontario
}

Volumes have been written on both forest surveys and working plans. This is neither a review of what has been written on these subjects nor an attempt to write a new text. It would also be futile to try to compile a detailed set of instructions for conducting a forest survey since operating companies have dissimilar forests, utilization problems and policies. Therefore, I would like to consider this as a starting point for a discussion on some of the more recent developments which have not yet become standard. ized and committed to text books and lecture notes.

Surveys and working plans are closely related. While planning the survey the operating and the working plan requirements should be reviewed so that it will be known what information must be obtained. The results of the survey should be compiled in such a manner that they will conform to the requirements. A general rule to follow is to compile the results on the smallest practicable area-units. Totals can be obtained by adding estimates on smaller units but estimates on small units cannot be obtained except by recompiling if large areas are compiled as a unit.

In standard texts the pros and cons of plots vs. continuous strip system of collecting samples may be reviewed. The plot in one form or another is gaining in popularity and $\mathrm{I}$ believe is most commonly used by pulp companies in Eastern Canada.

Getting the parties into the field, moving them from place to place, and servicing them will depend altogether upon the region, season and the facilities available. The standard means of transportation in Eastern Canada has been canoe or back-packing in summer and toboggans or sleighs hauled by hand or dog team in winter. Last winter we used a motor toboggan and, while its operation could not be regarded as 100 per cent, still it is good enough to use again next winter. Aircraft can be used in both summer and winter, sometimes with great advantage. It is not good enough for the party to be wholly dependent upon the plane but an alternative plan should always be made. If helicopters could compete in price and pay load they would be more useful to the survey party.

Road systems are rapidly being extended and these can often serve as a base from which a large area can be covered.

The most important advance in forest surveying has been the air photo. With greatly accelerated post-war photographic programs all the forested areas will soon be photographed and prints from these negatives can be purchased from the owners. The photos are of sufficient importance in the development and exploitation of the area as well as in the survey that they may be considered essential and no large survey should be undertaken without them. If the area has not been photographed and mapped already, or if the photos are so old that many changes have taken place in the forest

1. Paper presented at the fortieth annual meeting o: the Canadian Society of Forest Engineers, Fredericton, N.B., October 4 to $7,1948$. 
cover, or if the photos are otherwise unsatisfactory, there are several private air survey companies well equipped to do this type of work.

After obtaining the photos, some system of using them intelligently must be adopted. Even today companies secure photos and when the surveys or any field work are to be done they are left in the files in the office because personnel are not familiar with methods of using them. When air photos were first used in forest survey they were a sort of an appendage to ground survey. However, new methods are gradually being developed which recognize and use the factors which can be distinguished on the photos. For example, with photos of practicable scale for surveys, d.b.h. cannot be measured directly but crown diameter and height can be measured. It is quite possible that these factors can be used for volumetric estimates as well as d.b.h. Site is classified by correlating height and age, or by the presence of certain herbacious plants. Neither age nor plant species can be determined from photos but the position where the tree is growing in relation to slope and drainage can be determined, and this may be as good for site classification as any other. Certain factors such as recent burns or marshes can be determined from the photos directly, with little possibility of error: other factors can be deduced, for example, the ground should be wet in swamps. Factors such as age and amount of cull will have to be determined from ground examination. Personnel will have to be trained to interpret the photos.

If for operating or other purposes an intensive ground examination is necessary, I would recommend not doing much work on the photos until after the field survey has been completed. Then if the men do the photo classification in the field they are working with the advantage of just having been on the area and the conditions are still fresh in their minds. However, if only general information is required the photos should be studied and the information therefrom plotted on maps first. Then the field work can be reduced to sampling the cover types for volume or stand table purposes and reporting on the additional information as required. All errors observed in the office interpretation can be revised at this time. Operating companies will meet both these conditions and it is possible that so much of the first type of survey will be necessary that a modification of it will be used for the second instead of training a crew for both types. Others will probably use the second method with increased ground examination for operating purposes. This would be the normal course if the area is to be operated after having been surveyed by the second method some time previously.

As far as the working plan is concerned, we in Canada are very poorly equipped to prepare a plan comparable with models of those which are prepared for the management of European forests. Very little data is available on growth, re-establishment of the stand after cutting, silvicultural systems for the management of the different cover types, silvical characteristics of the species, etc.-all of which are essential for the preparation of a working plan. The best that can be done is to prepare the plan so as to conform with the requirements of the operation and the regulations of the province. Approximate yield curves can be determined by plotting yield 
over age. By examining old cut-over areas rough approximations regarding period for re-establishment of the stand can be arrived at. If the area allotment method or a modification of it is used for determining the annual cut, there is not the same need for accurate growth data.

The information so obtained can be checked against whatever growth data is available. In fact all results should be checked by using different methods wherever possible. Care should be taken to guard against high grading with the area allotment method.

All working plans should be revised at least every 10 years. In the interval, if sample plots are established in the important cover types and age classes as well as in cut-over areas, the data so collected can be used in revising the working plan.

At present we are developing a mechanical system of logging. This system has inherent characteristics which I am fully convinced will lead to and permit forest management to an extent not possible with the old manual system of pulpwood cutting. This new method has not had time to prove itself sufficiently to receive much publicity but results to date have been very satisfactory. Further experiments along these lines will lead to improved silvicultural systems and to more intensive forest management.

I will repeat that this is such a broad subject that all aspects of it can not be listed in a paper of this kind. Therefore, only a few of the more interesting and recent developments have been mentioned. 